\title{
461\%
}

\section{O Agora de Outrora: o cinema de Silas Tiny}

\author{
Sérgio Dias Branco
}

\section{Resumo:}

Este artigo analisa a obra do cineasta documental Silas Tiny, nascido em São Tomé e Príncipe, salientando a sua importância no modo como examina criticamente o período do poder colonial português sobre regiões africanas que se libertaram dessa dominação após o 25 de abril de 1974. O argumento principal que emerge da análise das suas duas longa-metragens é o de que o seu cinema documental se constrói a partir de imagens-dialécticas, no sentido que lhe é dado por Walter Benjamin e o seu pensamento crítico. A questão que ocupa Tiny é a da superação da relação temporal entre passado e presente por uma relação dialética entre o que foi (o outrora) e o que é (o agora). Bafatá, na Guiné-Bissau, é filmada pelo realizador em Bafatá Filme Clube (2012) como uma cidade-fantasma, povoada por espectros e aparições de defuntos num local à beira da extinção. O cinema é desta forma assumido como arte espectral que liga o presente ao passado, unindo a memória à ruína. Na obra seguinte, O Canto do Ossobó (2017), Tiny lida com as suas raízes pessoais. É, em simultâneo, um reencontro com São Tomé e um encontro com a sua história - ou talvez seja um encontro com esse lugar e um reencontro com a sua história. Este filme visa descobrir e preservar reminiscências, aquilo que lembra o passado, aquilo que 0 pode conservar na memória, mas sempre de forma incompleta e indefinida.

Palavras-chave: Cinema; Pós-colonialismo; Silas Tiny; Teoria Crítica.

\section{Abstract:}

This article analyzes the work of documentary filmmaker Silas Tiny, born in São Tomé and Príncipe, highlighting its importance in the way it critically examines the period of Portuguese colonial power over African regions that freed themselves from this domination after April 25, 1974. The main argument that emerges from the analysis of his two feature films is that his 
documentary cinema is built from dialectical images, in the sense given to it by Walter Benjamin and his critical thinking. The question that occupies Tiny is that of overcoming the temporal relationship between past and present by a dialectical relationship between what was (the former) and what is (the now). Bafatá, in Guinea-Bissau, is filmed by the director in Bafatá Filme Clube (2012) as a ghost town, populated by specters and apparitions of the dead in a place on the verge of extinction. Film is thus taken as a spectral art that links the present to the past, uniting memory and ruin. In the following work, O Canto do Ossobó (2017), Tiny tackles his personal roots. It is, simultaneously, a reunion with São Tomé and an encounter with its history — or perhaps it is an encounter with that place and a reunion with its history. This film aims at discovering and preserving reminiscences, that which resembles the past, that which can keep it in memory, but always in an incomplete and indefinite way.

Keywords: Critical theory; Film; Postcolonialism; Silas Tiny.

Silas Tiny nasceu no arquipélago de São Tomé e Príncipe em 1982. Tinham passado somente sete anos desde a independência. Era uma criança de cinco anos quando emigrou com a família para Portugal. Enquanto jovem, os primeiros campos artísticos que experimentou foram a pintura e a escultura. Depois entrou para a Escola Superior de Teatro e Cinema em 2010.

\section{Cidade-Fantasma: Bafatá Filme Clube}

Silas Tiny ainda era estudante da Licenciatura em Cinema quando realizou a sua primeira longa-metragem documental, Bafatá Filme Clube (2012), com o apoio do ICA - Instituto do Cinema e Audiovisual e da RTP - Rádio e Televisão de Portugal. O filme retrata a história da cidade de Bafatá, na Guiné-Bissau, importante local no período colonial, posteriormente desertificado. O retrato centra-se numa sala de cinema desativada, onde as atividades de um cineclube reuniam muita gente até à independência do país, declarada em 1973 e reconhecida em 1974. O edifício abandonado é guardado por Canjajá Mané, o antigo projecionista que repete os mesmos gestos há cinquenta anos mesmo sem espectadores. Canjajá nasceu em 1940.

Era pescador quando veio de Mansoa para trabalhar no Sporting Clube de Bafatá. Depois tornou-se responsável pela projeção de filmes, primeiro a carvão, mais tarde com energia elétrica e uma máquina alemã Bauer. Já está no Clube há mais de meio século, integrando a sua direção. "Continuamos a vida assim", diz ele.

O documentário foi produzido pela Real Ficção, produtora portuguesa fundada em 1986 pelo cineasta Rui Simões, que tem apostado na concretização de projetos, sobretudo documentais, de jovens realizadores, entre os quais se encontra Tiny (ver Cunha, 2015: 
127). A produtora Filmes do Mundo associou-se ao projeto. A Telecine Bissau coproduziu a obra do lado da Guiné-Bissau. Estas relações de produção são estruturantes de um olhar que se constrói entre Portugal e a sua ex-colónia africana. O ritmo é pausado, quotidiano, tecido de tarefas laborais e domésticas. As pessoas param para contar a sua estória, a da cidade, e a do Clube, como se estivessem a evocar uma única história, mas sempre contada de maneira diferente. Não há como contá-la sem falar da guerra pela independência, do 25 de Abril de 1974, do PAIGC - Partido Africano da Independência da Guiné e Cabo Verde, de Amílcar Cabral. Antes e até durante o conflito armado, o Clube somava sócios. As gentes locais gostavam e aderiam. Vinham dos arredores para ver cinema, porque era a única sala que tinha sido autorizada pelo poder colonial na região. A única alternativa eram as sessões de Manuel Joaquim, projetor ambulante.

Estes homens e estas mulheres perpetuam a memória para si e para quem os escuta, com muito desencanto e algum fatalismo. As atividades do Clube e as sessões de cinema, financiadas em grande parte pelos comerciantes de Bafatá, eram ocasiões para a reunião popular. A cidade era comparável a Bissau, um sítio de passagem, de trocas comerciais, de produção de joias e ourivesaria. Agora, é a imagem da decadência. Bafatá Filme Clube salienta o abandono, embora persistam múltiplos sinais de presenças, nas casas desabitadas, nos objetos envoltos em pó, nas zonas comuns que deixaram de ser utilizadas. A secura e o deserto invadiram tudo, criando ruínas como um tanque corroído que somos convidados a imaginar que foi outrora uma piscina. Mas esta situação, percebemos mais tarde, descreve apenas à parte baixa da cidade, onde se situa a sala do Bafatá Filme Clube. É uma área quase completamente abandonada e desligada. A parte alta, mais pequena, supostamente tem muita atividade, por ter um mercado, mais lojas, praças cheias, mas o filme nunca nos mostra esse outro lado da cidade. A sala é assim uma imagem do que persiste apenas porque há alguém que abre a porta, desempoeira os assentos, prepara a máquina de projeção, mesmo sem haver quem compre bilhete. O mesmo acontece com os poucos comerciantes que sobreviveram e que não têm clientes. Quanto desaparecerem, o mais provável é que esta secção de Bafatá morra também. O filme que Canjajá se prepara para projetar não chega a ser projetado. Não consegue atrair vivalma. O homem que mantém este hábito fecha a sala de cinema e afasta-se. Um dos entrevistados chama "cidade-fantasma" a Bafatá, mas também o será pela presença destas figuras que parecem espectros, aparições de defuntos num local à beira da extinção. O cinema é assumido por Tiny como arte espectral.

O cineasta regressou às ilhas de São Tomé e Príncipe em 2014 para mostrar este filme sobre a linha que liga o presente ao passado, entre os destroços e os fantasmas, unindo 
a memória à ruína (ver Arenas, 2017: 86), no âmbito da 7.ํㅗienal Internacional de São Tomé. Haviam passado quase três décadas desde que ele tinha deixado a sua terra natal. O reencontro com as suas raízes propiciou o projeto seguinte, O Canto do Ossobó (2017).

\section{Reminiscências: O Canto do Ossobó}

Ao contrário de Bafatá Filme Clube, que apenas foi exibido na televisão em Portugal (RTP e TVCine), O Canto do Ossobó estreou comercialmente no Cinema Ideal, em abril de 2018. Foi mostrado em diversos festivais, incluindo no DocLisboa 2017, onde integrou a competição nacional, e no Caminhos do Cinema Português 2018. É um filme mais pessoal e maduro que desenvolve o estilo plácido do documentário anterior, procurando captar pacientemente o ritmo das pessoas e das coisas que filma. É, em simultâneo, um reencontro com São Tomé e um encontro com a sua história. Ou talvez seja o contrário: um encontro com esse lugar e um reencontro com a sua história. Porque a lembrança que o cineasta tem da ilha que deixou quando ainda era menino talvez não permita o reencontro, já que nem as fotografias de família sobreviveram à viagem. Porque a memória que ele quer construir sobre a história desse lugar começou precisamente em Portugal, onde Tiny viveu quase toda a sua vida. São estas as razões para que a voz narradora dele seja tão importante, começando por evocar a sua história pessoal para a pouco e pouco trazer à memória a história coletiva do povo são-tomense. "Eu esqueci o meu passado como quem esquece um trauma difícil, uma recordação dolorosa", ouvimo-lo dizer enquanto deambula por escombros de edifícios escondidos pela vegetação, apagados pela névoa da passagem do tempo, e usados por animais como abrigo. Por isso, podemos dizer que os caminhos que o filme percorre visam a descoberta e preservação de reminiscências, daquilo que lembra o passado, aquilo que o pode conservar na memória, mas sempre de forma incompleta e indefinida. 0 realizador articula estas dimensões no seu discurso sobre o filme:

A construção de uma memória para mim enquanto cineasta traduz-se na criação de imagens que possam ser e repor o sentido de identidade. A imagem deixa de ser um elemento passivo e explicativo de alguma coisa e passa a ser ela mesma a presença daquilo que se perdeu. A imagem de uma árvore, de uma casa, não é para mim apenas uma representação, mas sim presença sensível - objeto da memória ligada a um significado e ao desejo de situar um sentimento passado no presente. Por isso, este filme pretende ser um espaço de observação onde se cruzam histórias, reflexões pessoais e espaços. Enfim, todo um território indistinguível correspondente não só a um sentimento pessoal, mas também coletivo, que para além de apelar a um país, ou a uma determinada geografia, apela também à construção da memória como forma de definição humana (citado em CEI-IUL, 2018). 
Rio do Ouro e Água Izé foram duas das maiores roças de produção de cacau (mas também de café e quina) do império colonial português. Como o próprio realizador explicou na altura da estreia, "A sua produção chegou a ser a maior a nível mundial nos princípios do século XX". As vidas de milhares de homens e mulheres em São Tomé foram marcadas pelo trabalho forçado num regime equiparado à escravatura. $O$ Canto do Ossobó indaga os vestígios desse passado de domínio, injustiça e dor. É como se tudo tivesse ficado, de alguma forma, em suspenso e se ouvisse, sob os sons do quotidiano atual, o silêncio de quem foi escravizado e morto. Os espaços permaneceram basicamente iguais e são eles que a câmara regista, através de enquadramentos fixos ou móveis, para que dar a ver a persistente presença do passado no presente.

Do passado, restam poucas imagens. A textura visual de O Canto do Ossobó combina imagens em vídeo de baixa e alta definição que sinalizam momentos de intimidade e de distanciamento, álbuns fotográficos que colecionam registos fugazes de encontros, e fotografias e filmes de arquivo a preto e branco. Estas últimas imagens aparecem na segunda parte do filme depois do narrador fornecer alguns dados históricos sobre o volume de negócios e as condições (encobertas) de escravatura em que as mercadorias transacionadas eram produzidas. Também a textura sonora do filme é densa, juntando um fundo de vozes impercetíveis ao chilreio dos pássaros, por vezes com música congénere, a um conjunto de vozes percetíveis que leem cartas, contam estórias, falam sobre a repressão colonialista, entre as quais se destaca a do realizador-narrador. 0 filme não parte da lembrança pessoal para compor a memória coletiva, vai cruzando esses planos, trabalhando-os na imagem e no som. Por exemplo, na praia de Fernão Dias, Tiny recorda o seu bisavô assassinado nesse local em fevereiro de 1953 e as centenas de outros homens torturados, enterrados, e lançados ao mar acusados de conspirarem contra o estado.

Em O Canto do Ossobó, as imagens e os sons têm uma força tão factual como evocativa. A dimensão evocativa é intensificada pela palavra, desde logo na expressão do título. O ossobó, ou cuco esmeraldino, é um pássaro cujo belo canto anuncia a chuva, mas que se esquiva ao olhar de quem quer contemplar a sua beleza. Conta a lenda que a sua distração levou a que fosse encantado por uma cobra matreira, desaparecendo sem deixar rasto. Esta narrativa serve de mote ao filme: a serpente hipnotizadora e muda e o ossobó hipnotizado e silenciado correspondem à aparência que cobria as plantações e o regime colonial. Como Tiny confessa no filme pela sua própria voz, ele não procurava apenas as suas recordações, mas também as dos outros, os momentos da vida dele que estavam contidos na história de quem o precedeu. 


\section{Conclusão: Imagens Dialéticas}

O próximo filme de Silas Tiny encontra-se em pós-produção e foi rodado em São Tomé, com o título Constelações do Equador. Trata-se de uma obra sobre a ponte área criada entre São Tomé e a Nigéria para transportar comida e medicamentos e salvar crianças da violência, no contexto da guerra civil nigeriana, depois da secessão do Biafra, em 1967. Neste momento, tem dois projetos em desenvolvimento: uma longa-metragem de ficção e o documentário Casa Decana que formará um díptico com O Canto do Ossobó sobre a temática da escravatura, no período colonial. Vale a pena refletir sobre o encadeamento destes projetos, deixando a análise fílmica para tirar algumas conclusões teóricas.

Numa entrevista concedida em 2017, Tiny foi questionado sobre o processo de filmagem e montagem de O Canto do Ossobó, mas a mesma pergunta podia ter sido feita sobre a forma cinematográfica de Bafatá Filme Clube. Talvez a diferença decisiva seja a ligação pessoal que o cineasta tem com São Tomé e Príncipe, que é mais ténue no caso da Guiné-Bissau. Eis a sua resposta:

Como é que se consegue mostrar o passado e falar dele, mas tendo em conta apenas o presente e o que nos rodeia? Todo o desenvolvimento do filme, teve em vista compreender esta questão. No filme existe uma tentativa interligar o presente e o passado, sem definir qualquer tipo de ordem cronológica à partida (Tiny, 2017: 16).

Tiny regressou ao seu país para encontrar vestígios de um passado de trabalho forçado nas roças de produção de cacau em O Canto do Ossobó. Estes vestígios tomam a forma de sinais fantasmáticos, uma espécie de assombrações, tal como aquelas que povoam Bafatá Filme Clube. Os filmes de Tiny ensaiam uma busca pelo passado sem sair do presente, um modo de não quebrar a interligação entre os tempos. Trata-se de um trabalho que se confunde, no caso dele e como ele próprio confessa, com o interesse pelo cinema como arte (Tiny, 2017: 16). Parece interessar-lhe a construção de imagens dialéticas, no sentido benjaminiano, através das imagens cinematográficas, como muito apropriadamente refere Michelle Sales (2019: 327). Escreveu Walter Benjamin sobre este tipo de imagens e a sua autenticidade: "Não se pode dizer que o passado lança a sua luz sobre o presente, nem que o presente lança a sua luz sobre o passado; a imagem é antes aquilo em que em que o já foi converge com o agora numa constelação fulminante." (2019: 592). O facto de um dos próximos projetos do cineasta mencionar o conceito imagético de constelações no seu título demonstra como o seu trabalho se aproxima do pensamento do filósofo alemão. Como Benjamin desenvolve, a questão que o ocupa é a da superação da relação temporal entre passado e presente por uma relação dialética entre o que foi (o outrora) e o que é (o agora). Ler Bafatá Filme Clube 
e O Canto do Ossobó, como procurei fazer brevemente, é aproveitar a possibilidade de conhecimento aberta pelo agora das suas imagens. Isso "traz consigo em alto grau a marca do momento crítico, perigoso, subjacente a toda a leitura" (Benjamin, 2019: 592). Este é um cinema em que o risco necessário para a construção de um olhar crítico e desimpedido é partilhado entre quem cria as imagens e quem as lê.

\section{Referências bibliográficas}

Arenas, F. (2017). The Filmography of Guinea-Bissau's Sana Na N'Hada: From the Return of Amílcar Cabral to the Threat of Global Drug Trafficking. Portuguese Literary \& Cultural Studies, 30/31, 68-94. Consultado em: https://ojs.lib.umassd.edu/index.php/plcs/article/view/PLCS30_31_Arenas_page68/122 3

Benjamin, W. (2019). As Passagens de Paris. Lisboa, Portugal: Assírio \& Alvim.

CEI-IUL. (2018). 18 OUT | Activisms in Docs: O Canto de Ossobó. Changing World, 18 Out. Consultado em: https://blog.cei.iscte-iul.pt/18-out-activisms-in-docs-o-canto-deossobo.

Cunha, P. (2015). Cinema de Garagem: Distribuição e Exibição de Cinema em Portugal. In F. Lopes, P. Cunha, e M. Penafria (Eds.), Cinema em Português: VII Jornadas (pp. 117-137). Covilhã, Portugal: Editora LabCom.IFP.

Sales, M. (2019). Cinema Negro Português. In A. Costa Valente (Ed.), Avanca /Cinema 2019 (pp. 325-329). Avanca: Edições Cine-Clube de Avanca.

Tiny, S. (2019). Entrevista. In doclisboa'17 / Projecto Educativo (p. 16). Lisboa, Portugal: Apordoc - Associação pelo Documentário, 2017. Consultado em: http://www.doclisboa.org/2017/wp-content/uploads/dossier-projecto-educativo.pdf.

Tiny, S. (Realizador). (2012). Bafatá Filme Clube [Filme]. Portugal: Real Ficção.

Tiny, S. (Realizador). (2017). O Canto do Ossobó (Filme). Portugal: Real Ficção. 
Sérgio Dias Branco é Professor Auxiliar de Estudos Fílmicos na Universidade de Coimbra. É diretor do Mestrado em Estudos Artísticos e coordenador do LIPA - Laboratório de Investigação e Práticas Artísticas. Lecionou na Universidade Nova de Lisboa e na Universidade de Kent, onde se doutorou em Estudos Fílmicos. É investigador integrado do Centro de Estudos Interdisciplinares do Século XX (CEIS20) da Universidade de Coimbra e membro convidado do grupo de análise fílmica da Universidade de Oxford, The Magnifying Class. O seu trabalho de investigação tem como foco a estética e poética de obras da imagem em movimento, nas suas relações com a filosofia, a história, o marxismo, e a religião. Foi membro da Direção da AIM Associação de Investigadores da Imagem em Movimento entre 2014 e 2020, assumindo as funções de presidente entre 2018 e 2020.

凶sdiasbranco@fl.uc.pt 